\title{
Investigation of luminescent properties inherent to $\mathrm{SrTiO}_{3}: \mathrm{Pr}^{3+}$ luminophor with $\mathrm{Al}$ impurity
}

\author{
O.M. Marchylo ${ }^{1}$, L.V. Zavyalova ${ }^{1}$, Y. Nakanishi ${ }^{2}$, H. Kominami ${ }^{2}$, A.E. Belyaev ${ }^{1}$, G.S. Svechnikov ${ }^{1}$ \\ ${ }^{1}$ V. Lashkaryov Institute of Semiconductor Physics, National Academy of Sciences of Ukraine, \\ 41, prospect Nauky, 03028 Kyiv, Ukraine \\ ${ }^{2}$ Research Institute of Electronics, Shizuoka University, \\ 3-5-1 Johoku, Naka-ku, Hamamatsu 432-8011, Japan
}

\begin{abstract}
The red-emitting $\mathrm{SrTiO}_{3}: \mathrm{Pr}^{3+}, \mathrm{Al}$ luminophors that can be used for the white light emitting diodes (LEDs) were prepared using the sol-gel method. The starting materials were $\mathrm{SrCl}_{2}, \mathrm{Ti}\left(\mathrm{O}-\mathrm{i}-\mathrm{C}_{3} \mathrm{H}_{7}\right)_{4}, \mathrm{Al}\left(\mathrm{NO}_{3}\right)_{3} \cdot 9 \mathrm{H}_{2} \mathrm{O}$ and $\mathrm{PrCl}_{3}$. The reaction between them results in a mixture of compounds that transform into single-phase $\mathrm{SrTiO}_{3}: \mathrm{Pr}^{3+}, \mathrm{Al}$ after annealing in air. Displacement of Ti out of the $\mathrm{SrTiO}_{3}$ lattice caused by substitution with $\mathrm{Al}$ and formation of individual crystalline $\mathrm{TiO}_{2}$ phase (rutile) were observed. PL spectra show the high-intense red peak $(\lambda=617 \mathrm{~nm})$, the same high-intense peak with the full width at half maximum (FWHM) $20 \mathrm{~nm}$ was found in cathodoluminescence spectra. The increase of the aluminium concentration from 0 up to 15 mol.\% leads to approximately two-fold increase in the luminance. The latter increases from 180 up to $350 \mathrm{~cd} / \mathrm{m}^{2}$ at the anode voltage $10 \mathrm{kV}$ and current density $30 \mu \mathrm{A} / \mathrm{cm}^{2}$.
\end{abstract}

Keywords: luminophor, $\mathrm{SrTiO}_{3}: \mathrm{Pr}^{3+}, \mathrm{Al}$, photoluminescence, cathodoluminescence, LED.

Manuscript received 21.07.11; revised manuscript received 29.08.11; accepted for publication 14.09.11; published online 30.11.11.

\section{Introduction}

In recent years, white light emitting diodes (LED) have been considered as a next generation of solid-state light sources and used in many applications related with their advantages, namely, their long operation lifetime and low energy consumption [1-2]. A new method to obtain white light is using near UV InGaN-based LEDs covered by RGB-tricolor luminophors (red, green and blue). Commercial red-emitting luminophor for white LEDs is $\mathrm{Y}_{2} \mathrm{O}_{2} \mathrm{~S}: \mathrm{Eu}^{3+}$ that has lower efficiency, shorter operation lifetime under UV irradiation as compared with blue and green luminophors. Moreover, it has instability caused by appearance of sulfide gas [3]. Further, the emission color of $\mathrm{Y}_{2} \mathrm{O}_{2} \mathrm{~S}: \mathrm{Eu}^{3+}$ is inadequate. One of important tasks in LED technologies is search of luminophors with high performances. Therefore, many efforts are devoted to develop new luminophors for white LEDs. Especially, red emitting luminophors with a high luminance and good color purity are required. Based on this background, the red emitting luminophors for LEDs are currently under investigation. For example, red-emitting $\mathrm{SrTiO}_{3}: \mathrm{Pr}^{3+}$ luminophor has been investigated and characterized [4-7]. Essential enhancement of the emission intensity of $\mathrm{SrTiO}_{3}: \mathrm{Pr}^{3+}$ can be obtained by $\mathrm{Al}$ addition [8]. Impurity of $23 \mathrm{~mol} . \% \mathrm{Al}$ intesifies emission by more than 200 times. As shown earlier, the $\mathrm{SrTiO}_{3}: \mathrm{Pr}^{3+}$ luminophor demonstrates high luminescent characteristics and can be rather promising material for LEDs. So far, $\mathrm{SrTiO}_{3}: \mathrm{Pr}^{3+}$ luminophors have been synthesized by mixing $\mathrm{SrCO}_{3}, \mathrm{TiO}_{2}, \mathrm{PrCl}_{3}$ and $\mathrm{Al}(\mathrm{OH})_{3}$ with the subsequent sintering and crushing the prepared powder.

In this work, to synthesize $\mathrm{SrTiO}_{3}: \mathrm{Pr}^{3+}, \mathrm{Al}$ we used the sol-gel method with $\mathrm{SrCl}_{3}$, Ti $\left(\mathrm{O}-\mathrm{i}-\mathrm{C}_{3} \mathrm{H}_{7}\right)_{4}, \mathrm{PrCl}_{3}$ and $\mathrm{Al}\left(\mathrm{NO}_{3}\right)_{3} \cdot 9 \mathrm{H}_{2} \mathrm{O}$ as starting materials. By using this method, we managed to get more complete reactions between the starting materials and to obtain more uniform distribution of the doped materials in the host lattice. In this paper, we report about the influence of Aladdition to luminophor $\mathrm{SrTiO}_{3}: \mathrm{Pr}^{3+}$ on its structural and luminescent properties. 


\section{Synthesis of samples}

The studied $\mathrm{SrTiO}_{3}: \mathrm{Pr}^{3+}, \mathrm{Al}$ luminophors were synthesized using the sol-gel method similar to that in [9] (Fig. 1). Starting materials were strontium chloride $\mathrm{SrCl}_{2}$, praseodymium chloride $\mathrm{PrCl}_{3}$, aluminium nitrate 9-hydrate $\mathrm{Al}\left(\mathrm{NO}_{3}\right)_{3} \cdot 9 \mathrm{H}_{2} \mathrm{O}$ and titanium tetra-i-propoxide $\mathrm{Ti}\left(\mathrm{O}-\mathrm{i}-\mathrm{C}_{3} \mathrm{H}_{7}\right)_{4}$. Synthesis was carried out in nitrogen atmosphere. A ratio of starting materials was $\mathrm{Sr} / \mathrm{Ti}=1$ and concentration of $\operatorname{Pr}^{3+}$ was fixed at $1 \mathrm{~mol} . \%$. The aluminium concentration was varied from 0 to $15 \mathrm{~mol} . \%$. The starting materials were dissolved in an ethanol $96 \%$ (with water content of $4 \%$ ) and stirred for 3 hours. Dissolution was not observed when $\mathrm{SrCl}_{2}$ and $\mathrm{PrCl}_{3}$ were mixed with the dehydrated ethanol as well as with dehydrated methanol. Complete dissolution was observed when $\mathrm{SrCl}_{2}$ and $\mathrm{PrCl}_{3}$ were mixed with ethanol containing $4 \% \mathrm{H}_{2} \mathrm{O}$. This suggests that water plays the primary role in the process of $\mathrm{SrCl}_{2}$ and $\mathrm{PrCl}_{3}$ dissolution despite its small amount. Alcohol is necessary for uniform distribution of small amounts of water throughout the reactionary volume. Besides, water apparently acts as the reagent that interacts with the titanium tetra-i-propoxide titanium $\mathrm{Ti}\left(\mathrm{O}-\mathrm{i}-\mathrm{C}_{3} \mathrm{H}_{7}\right)_{4}$, resulting in formation of titanium hydroxide $\mathrm{Ti}(\mathrm{OH})_{4}$. This is shown in transformation of transparent colorless solution containing $\mathrm{SrCl}_{2}$ and $\mathrm{PrCl}_{3}$ into the white gellike substance. Apparently, it is caused by the reaction:

$\mathrm{Ti}\left(\mathrm{O}-\mathrm{i}-\mathrm{C}_{3} \mathrm{H}_{7}\right)_{4}+4 \mathrm{H}_{2} \mathrm{O} \rightarrow \mathrm{Ti}(\mathrm{OH})_{4}(\mathrm{gel})+4 \mathrm{C}_{3} \mathrm{H}_{7} \mathrm{OH}$.

Then solvent was evaporated (under the further stirring) until the gel was obtained. This gel was dried at the temperature $150{ }^{\circ} \mathrm{C}$ and sintered in a muffle furnace CNOL 6.7/1300. Sintering was carried out in air under the optimal temperature regime and time of annealing, $1300^{\circ} \mathrm{C}$ and 3 hours, respectively [9]. Finally, the obtained material was crushed into powder.

\section{Results and discussion}

\subsection{Morphology and XRD-analysis}

To measure the size of particles, the alcohol suspension of $\mathrm{SrTiO}_{3}: \mathrm{Pr}^{3+}$,Al powder was dispersed on a glass substrate. The surface morphology was investigated with raster microscope REM-102E by using the method secondary-emission of electrons. Morphology of $\mathrm{SrTiO}_{3}: \mathrm{Pr}^{3+}$,Al particles on glass surface is presented in Fig. 2. In this figure, the arrow shows a single grain of the most probable size. The crystal sizes mainly varied within the range 1 to $5 \mu \mathrm{m}$ and a small amount of crystals and their conglomerates have sizes up to $10 \mu \mathrm{m}$.

The structural analysis of the prepared luminophors was carried out using the X-ray diffractometer DRON $-3 \mathrm{M}$ with $\mathrm{CuK}_{\alpha}$ radiation $(\lambda=1.542 \AA)$. The samples containing various concentrations of aluminium were annealed at $1300{ }^{\circ} \mathrm{C}$ for 5 hours and investigated. Fig. 3 shows that Pr- and Al-containing starting materials do not form individual crystalline compounds in the final product, but incorporate into the crystal lattice of $\mathrm{SrTiO}_{3}$ and replace $\mathrm{Sr}$ and $\mathrm{Ti}$, respectively. This substitution occurs because of the proximity values of ionic radii of $\mathrm{Pr}$ and $\mathrm{Sr}, \mathrm{Al}$ and $\mathrm{Ti}$, respectively, which is consistent with the results reported in $[4,6]$. Thus, $\mathrm{Al}$ replaces $\mathrm{Ti}$ in the lattice $\mathrm{SrTiO}_{3}$, which leads to deterioration of the crystallinity. Moreover, $\mathrm{Ti}$ is displaced from the lattice $\mathrm{SrTiO}_{3}$ and forms the individual crystalline phase of $\mathrm{TiO}_{2}$-rutile.

We assume that formation of $\mathrm{SrTiO}_{3}$ can be represented by the following processes:

1. Gel formation:

$\mathrm{Ti}\left(\mathrm{O}-\mathrm{i}-\mathrm{C}_{3} \mathrm{H}_{7}\right)_{4}+4 \mathrm{H}_{2} \mathrm{O} \rightarrow \mathrm{Ti}(\mathrm{OH})_{4}+4 \mathrm{C}_{3} \mathrm{H}_{7} \mathrm{OH}$.

\section{Annealing:}

a) $\mathrm{Ti}(\mathrm{OH})_{4} \rightarrow\left(600-800^{\circ} \mathrm{C}\right) \rightarrow \mathrm{TiO}_{2}+2 \mathrm{H}_{2} \mathrm{O}$;

b) $2 \mathrm{SrCl}_{2}+\mathrm{O}_{2} \rightarrow\left(1000-1250^{\circ} \mathrm{C}\right) \rightarrow 2 \mathrm{SrO}+2 \mathrm{Cl}_{2}$.

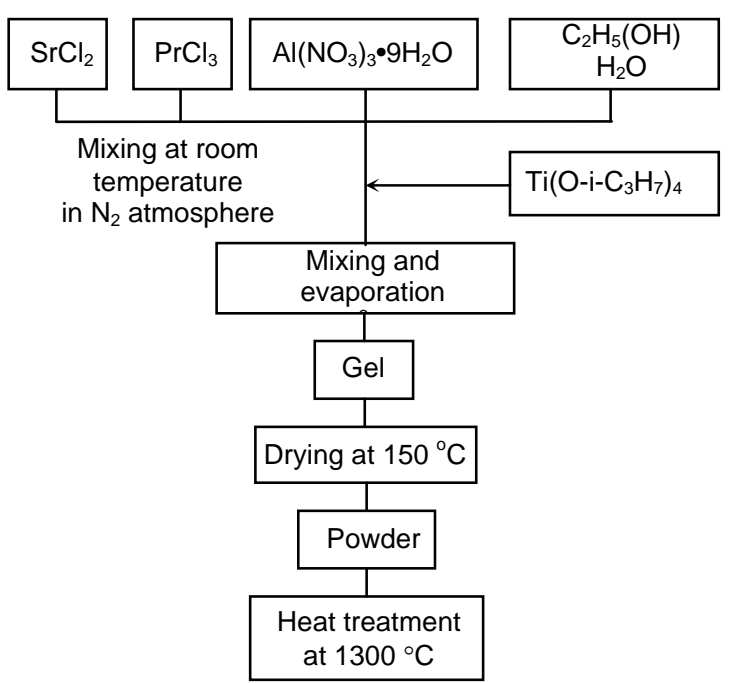

Fig. 1. Preparation of $\mathrm{SrTiO}_{3}: \mathrm{Pr}^{3+}, \mathrm{Al}$ luminophor.

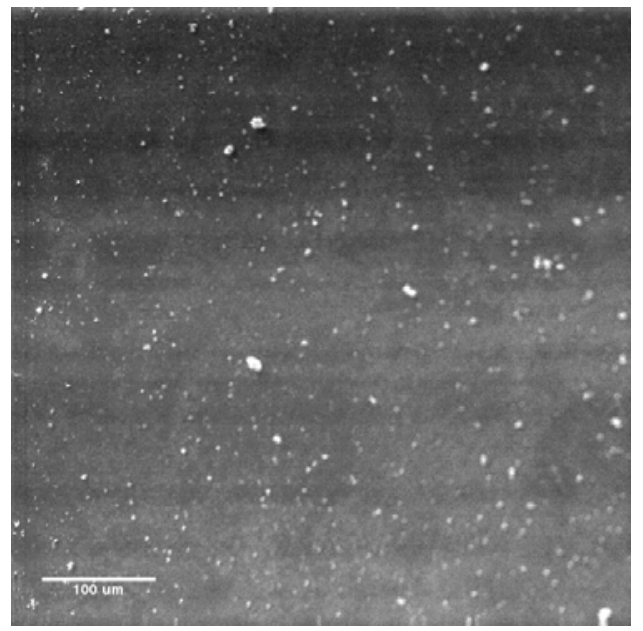

Fig. 2. Microrelief of a glass surface with crystals of $\mathrm{SrTiO}_{3}: \mathrm{Pr}^{3+}, \mathrm{Al}$ luminophor. 


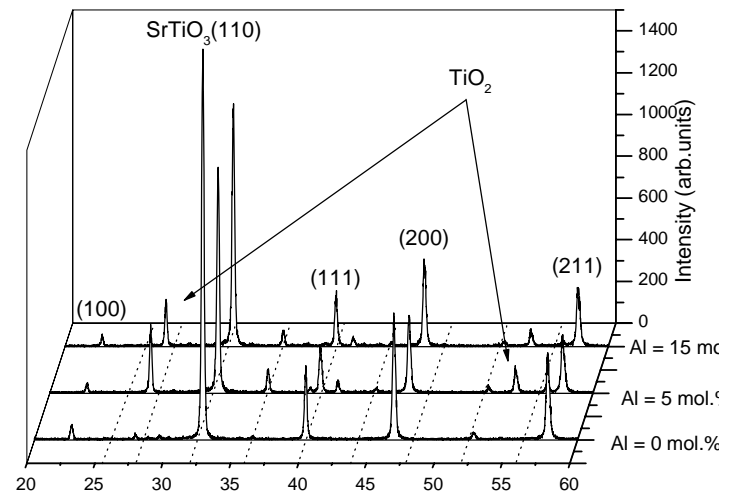

Fig. 3. XRD spectra of the samples with various $\mathrm{Al}$ concentrations.

\section{Structuring:}

$\mathrm{TiO}_{2}+\mathrm{SrO} \rightarrow\left(1000-1250{ }^{\circ} \mathrm{C}\right) \rightarrow \mathrm{SrTiO}_{3}$.

Thus, decomposition of titanium hydroxide and formation of strontium oxide occur at different temperatures, so they could not take place simultaneously.

\subsection{Photoluminescence spectra}

Photoluminescence (PL) spectra were measured within the wavelength range 450 to $750 \mathrm{~nm}$ under nitrogen laser (wavelength $337 \mathrm{~nm}$, pulse duration $8 \mathrm{~ns}$ ) excitation at the width of measuring strobe of $75 \mu$ s. Fig. 4 shows the typical PL spectrum of the sample $\mathrm{SrTiO}_{3}: \mathrm{Pr}^{3+}$ with no additional $\mathrm{Al}$ annealed at $1300{ }^{\circ} \mathrm{C}$ for $5 \mathrm{~h}$. The PL spectrum has three peaks, the highest intensity is observed for the peak at $\lambda=617 \mathrm{~nm}$. Blue emission with its maximum at $\lambda_{\max 1}=488 \mathrm{~nm}$ corresponds to the intra$4 \mathrm{f}$ transition from the excited state ${ }^{3} \mathrm{P}_{0}$ to the ground state ${ }^{3} \mathrm{H}_{4}$ of $\mathrm{Pr}^{3+}$, green emission with the maximum at $\lambda_{\max 2}=$ $530 \mathrm{~nm}$ corresponds to the intra-4f transition from the excited state ${ }^{3} \mathrm{P}_{1}$ to the state ${ }^{3} \mathrm{H}_{5}$, and red emission with the maximum at $\lambda_{\max 3}=617 \mathrm{~nm}$ corresponds to the intra4f transition from the excited state ${ }^{1} \mathrm{D}_{2}$ to the ground state ${ }^{3} \mathrm{H}_{4}[8,10,11]$.

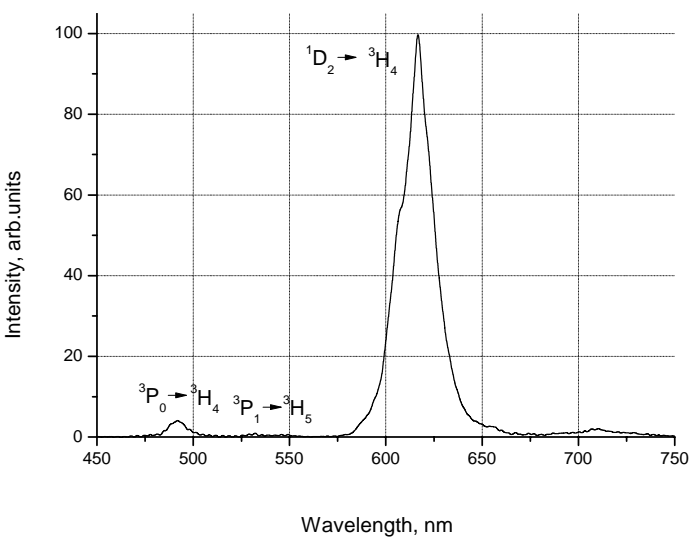

Fig. 4. $\mathrm{PL}$ spectrum of the sample $\mathrm{SrTiO}_{3}: \mathrm{Pr}^{3+}$.
The used increase in aluminium concentration from 0 up to $15 \mathrm{~mol} \%$ results in a slight growth of the intensity of the main peak $\lambda_{\max 3}=617 \mathrm{~nm}$ (Fig. 5). Thus, when the aluminum concentration is changed from 0 up to $5 \mathrm{~mol} . \%$, an increase in the photoluminescence intensity by $20 \%$ is observed. However, the further increase in concentration from 5 to $15 \mathrm{~mol} \%$ leads to insignificant decrease in the peak intensity $\lambda_{\max 3}$ (Fig. 5, insert).

\subsection{Cathodoluminescence spectra}

Cathodoluminescence (CL) was also investigated under the electron beam excitation (current density $30 \mu \mathrm{A} / \mathrm{cm}^{2}$, anode voltage 2 to $10 \mathrm{kV}$ ). The same samples of $\mathrm{SrTiO}_{3}: \mathrm{Pr}^{3+}, \mathrm{Al}$ were investigated. The typical CL spectrum of the sample $\mathrm{SrTiO}^{3}: \mathrm{Pr}^{3+}, \mathrm{Al}$ and its comparison with PL spectra are shown in Fig. 6. It is appeared that the shape of these spectra is completely identical, and no shifts of the main peaks or redistribution of their intensities is not observed. Both, PL and CL spectra have the same intensity of red peak with 20-nm FWHM.

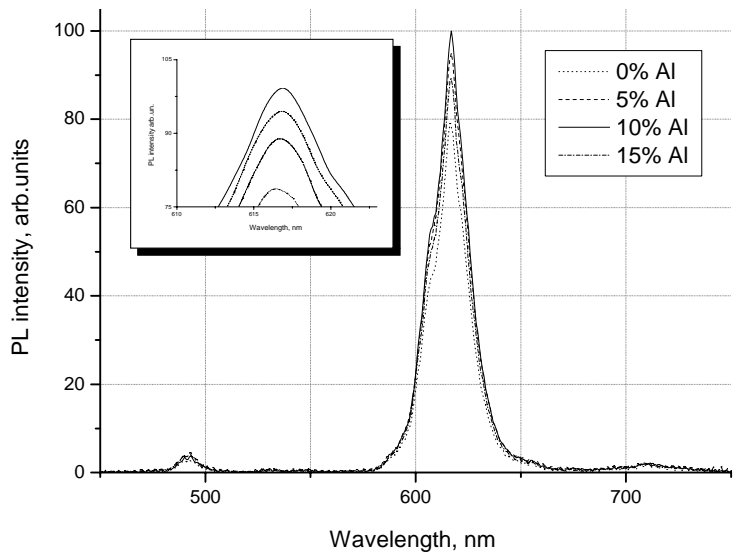

Fig. 5. PL spectra of the samples with various Al concentrations.

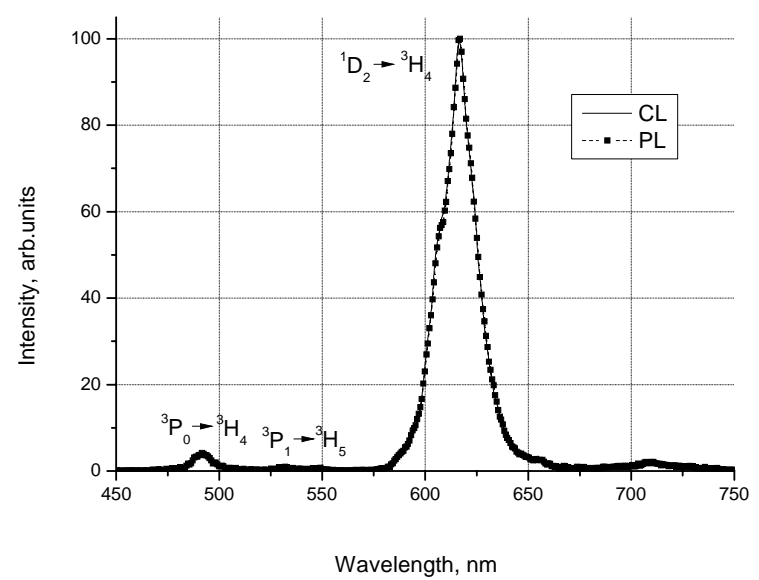

Fig. 6. $\mathrm{CL}$ and $\mathrm{PL}$ spectra of luminophor $\mathrm{SrTiO}_{3}: \mathrm{Pr}^{3+}, \mathrm{Al}(\mathrm{Al}=$ $15 \mathrm{~mol} . \%$ ), the former being measured at $V_{a}=2 \mathrm{kV}$, $J_{s}=30 \mu \mathrm{A} / \mathrm{cm}^{2}, P=7.8 \times 10^{-9}$ Torr, adduced together for comparison. 


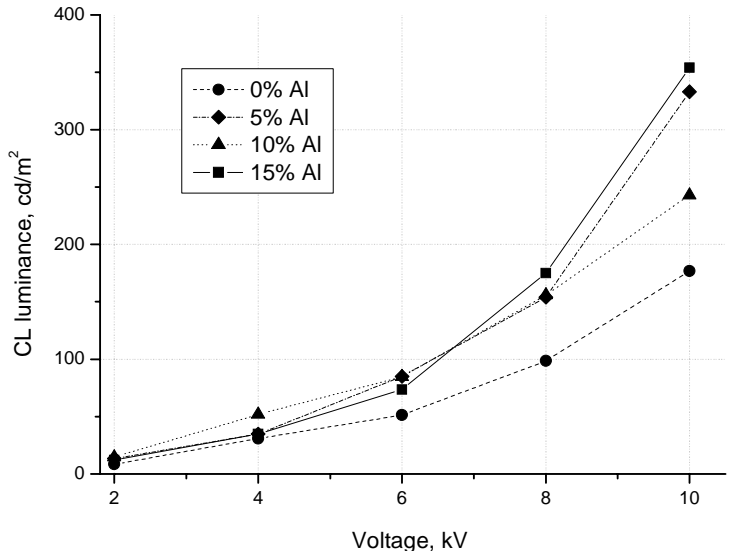

Fig. 7. Dependence of CL luminance on the anode voltage for various $\mathrm{Al}$ concentrations. $J_{s}=30 \mu \mathrm{A} / \mathrm{cm}^{2} ; P=7.8 \times 10^{-9}$ Torr.

The CL intensity measurements with increasing the anode voltage show that the samples with no aluminium addition have the luminance $177 \mathrm{~cd} / \mathrm{m}^{2}$. The increase in aluminium concentration from 0 up to 5 mol.\% leads to the 2-fold increase in luminance, and the latter reaches $333 \mathrm{~cd} / \mathrm{m}^{2}$ at the anode voltage close to $10 \mathrm{kV}$ (Fig. 7). A further increase in aluminum concentration from 5 to 15 mol.\% does not lead to any significant enhance in luminance as it was reported in [8]. The maximum CL luminance is observed at the concentration of aluminium $15 \mathrm{~mol} \%$, and it reaches $354 \mathrm{~cd} / \mathrm{m}^{2}$.

Thus, for the samples $\mathrm{SrTiO}_{3}: \mathrm{Pr}^{3+}$ the high luminance $177 \mathrm{~cd} / \mathrm{m}^{2}$ was obtained. The Al-addition of $15 \mathrm{~mol} . \%$ leads to increase in luminance by 2 times, and it reaches $354 \mathrm{~cd} / \mathrm{m}^{2}$. These results are not consistent with the data reported in the paper [8]. It was reported earlier that initially $\mathrm{SrTiO}_{3}: \mathrm{Pr}^{3+}$ has an extreme low luminance of the luminescence and only aluminium addition can increase it by more than 200 times. Therefore, such a discrepancy between the results requires further researches.

\section{Conclusions}

It has been shown that mixture of compounds $\mathrm{SrCl}_{2}$, $\mathrm{Ti}\left(\mathrm{O}-\mathrm{i}-\mathrm{C}_{3} \mathrm{H}_{7}\right)_{4}, \mathrm{PrCl}_{3}$ and $\mathrm{Al}\left(\mathrm{NO}_{3}\right)_{3} \cdot 9 \mathrm{H}_{2} \mathrm{O}$ can be transformed to $\mathrm{SrTiO}_{3}: \mathrm{Pr}^{3+}, \mathrm{Al}$ under definite technological conditions. Herewith, displacement of $\mathrm{Ti}$ out of $\mathrm{SrTiO}_{3}$ lattice due to substitution with $\mathrm{Al}$ and formation of the individual crystalline $\mathrm{TiO}_{2}$-rutile phase take place.

The increase in aluminium concentration from 0 up to $15 \mathrm{~mol} . \%$ results in a slight growth of the intensity of the main peak $\lambda_{\max 3}=617 \mathrm{~nm}$. Simultaneously, the increase in aluminium concentration from 0 up to 15 mol.\% leads to the 2 -fold increase in luminance, and the latter reaches $354 \mathrm{~cd} / \mathrm{m}^{2}$ at the anode voltage value $10 \mathrm{kV}$ and current density $30 \mu \mathrm{A} / \mathrm{cm}^{2}$ (Fig. 7).
A further increase in aluminum concentration from 5 to $15 \mathrm{~mol} \%$ does not lead to significant enhance in luminance, as it was reported in [8]. The maximum CL luminance is observed at the concentration of aluminum $15 \mathrm{~mol} . \%$, and its value reaches $354 \mathrm{~cd} / \mathrm{m}^{2}$.

It has been found a significant difference between the PL and CL data reported in this paper as compared with the data reported earlier. This discrepancy between the results requires further researches.

Thus, it has been shown that luminophor $\mathrm{SrTiO}_{3}: \mathrm{Pr}^{3+}$, Al prepared using the sol-gel method is promising material for further researches and applications as the red-emitting one for white light emitting diodes.

\section{Acknowledgements}

We are grateful to Dr. E. Manoilov for the PL measurements, Dr. A. A. Korchevoi for XRD measurements and V.I. Poludin for microrelief measurements.

\section{References}

1. H. Amano, M. Kito, K. Hiramatsu, and I. Akasaki // Jpn. J. Appl. Phys. 28, p. 2112-2114 (1989).

2. S. Nakamura, T. Mukai, and M. Senoh // Appl. Phys. Lett. 64, p. 1687-1689 (1994).

3. H. Junli, Z. Liya, L. Zhaoping, G. Fuzhong, H. Jianpeng, W. Rongfang // J. Rare Earths, 28(3), p. 356-360 (2010).

4. S. Itoh, H. Toki, K. Tamura and F. Kataoka // Jpn. J. Appl. Phys., 38(11), p. 6387-6391 (1999).

5. S. Okamoto, S. Tanaka and H. Yamamoto // Electrochem. and Solid-State Lett., 3(5), p. 242-244 (2000)

6. J.Y. Kim, Y.C. You and D.Y. Jeon // J. Vac. Sci. Technol. B, 21(1), p. 536-539 (2003).

7. Y. Inaguma, D. Nagasawa and T. Katsumata // Jpn. J. Appl. Phys., 44(1B), p. 761-764 (2005).

8. S. Okamoto, H. Kobayashi, H. Yamamoto // J. Electrochem. Soc., 147(6), p. 2389-2393 (2000).

9. O. Marchylo, L. Zavyalova, Y. Nakanishi, H. Kominami, K. Hara, A. Belyaev, G. Svechnikov, L. Fenenko, V. Poludin // Semiconductor Physics, Quantum Electronics \& Optoelectronics, 12(4), p. 321-323 (2009).

10. K. Horikawa, M. Kottaisamy, H. Kominami, T. Aoki, N. Azuma,T. Nakamura, Y. Nakanishi and Y. Hatanaka // Bulletin of Reasearch Institute of Electronics, Shizuoka University, 33, p. 31-36 (1998).

11. H. Kominami, M. Tanaka, Y. Nakanishi, Y. Hatanaka // Phys. status solidi (c), 3, No.8, p. 2758-2761 (2006). 